\title{
Analysis of the Stress State in Steel Components Using Portable X-Ray Diffraction
}

\author{
S.A. Nikulin, S.L. Shitkin, A.B. Rozhnov, S.O. Rogachev \\ and T.A. Nechaykina
}

\begin{abstract}
Comparative measurements have been performed on 20GL steel and grade 2 steel samples put under load in the elastic area in a three-point bending test to evaluate stress using stationary and new developed portable X-ray diffractometer. The results obtained showed that there was a good concurrence in the stress values measured by the stationary and portable diffractometers to within an accuracy of $10 \%$ (adjusted for calculation and measurement errors). The experimental results confirm the promising outlook for the practical application of developed portable $\mathrm{X}$-ray diffractometer.
\end{abstract}

Keywords Railway transport components - X-ray diffraction - Residual stress Portable X-ray diffractometer

\section{Introduction}

The X-ray technique occupies a special place among existing non-destructive testing methods of measuring mechanical stresses in metals and alloys such as ultrasonic [1, p. 750], magnetic [2, p. 620; 3, p. 9], laser-interferometric [4, p. 45], acoustic $[4$, p. 46] and other methods, because it is the only direct non-destructive

S.A. Nikulin · A.B. Rozhnov ( $₫)$ - S.O. Rogachev · T.A. Nechaykina National Science and Technology University MISiS, Moscow, Russia e-mail: rojnov@nm.ru
S.A. Nikulin
e-mail: nikulin@misis.ru
S.O. Rogachev
e-mail: csaap@mail.ru

T.A. Nechaykina

e-mail: nechaykinata@gmail.com

\section{S.L. Shitkin}

Joint Stock Company Railway Research Institute, Moscow, Russia

e-mail: shitkins@yandex.ru 
method of residual stress evaluation as it offers direct measurement of the crystal lattice deformation by displacement of diffraction peaks $[5$, p. $367 ; 6$, p. $12 ; 7$, p. 201]. Although it achieves stress measurements with high accuracy, the X-ray method requires a special preparation of the surface of a measured specimen. The measurement tool which the technique relies on is the X-ray quantas having wavelength which is commensurate with the measured spacing in the crystal lattice of a metallic structure, and the reflection angle from the crystal lattice planes is strongly correlated with the wavelength of X-ray radiation and the lattice spacing in a crystalline sample and is governed by the diffraction equation. The X-ray method to measure surface stresses which is used in the diffractometer is based on the registration of diffraction peaks which shift relative to their unstressed position on the surface of a specimen.

In order to ensure radiation safety, modern diffractometers use "soft X-rays" with a quantum energy not greater that $20-30 \mathrm{keV}$ which allow residual stress measurements through the thickness of a thin surface layer equal to the penetration depth of X-rays (not exceeding a few tens of micrometers for steel [8, p. 102]). This feature allows measurement of only surface stresses using an X-ray method.

Following stationary X-ray diffractometers used for laboratory measurements, portable X-ray diffractometers that appeared a few years ago can be taken out into field for measurements of stresses in a structural material or component. This is partly due to the adoption of a new solution built on the application of a non-focusing X-ray optics technique for the parallel primary beam (The Debye-Scherrer Scheme) which makes not only the parallel surfaces of a specimen, but all crystal lattice planes involved in the diffraction process [9, p. 317, 5. p. 73].

Introduction of new methods, technologies, and diagnostic equipment often requires special tuning or ad hoc adjustments, which may result in a number of comparative verification tests to be conducted. This paper describes the results obtained from verification testing of an originally developed portable X-ray diffractometer onto steel samples cut out from railway transport components.

\section{Materials for Analysis}

Two types of steel materials were used in this study: 20GL steel (used for solebars of a bogie frames) and grade 2 steel under Russian Standart 10791 (used for railway wheels). The chemical composition of the two types of steel is shown in Table 1. Samples having a length of $60 \mathrm{~mm}$, width of $10 \mathrm{~mm}$ and thickness of $1 \mathrm{~mm}$ were cut out by the method of electro-erosive cutting from full-scale railway transport components. The samples were studied in the normalized condition, but some samples were additionally annealed at $600{ }^{\circ} \mathrm{C}$ with $1 \mathrm{~h}$ exposure and slow cooling (with furnace). 
Table 1 The chemical composition of the steel samples cut out from railway transport parts

\begin{tabular}{l|l|l|l|l|l|l|l|l|l}
\hline \multirow{2}{*}{ Steel } & \multicolumn{8}{l}{ Chemical composition, mass\% } \\
\cline { 2 - 11 } & $\mathrm{C}$ & $\mathrm{Mn}$ & $\mathrm{Si}$ & $\mathrm{Cr}$ & $\mathrm{Ni}$ & $\mathrm{Cu}$ & $\mathrm{P}$ & $\mathrm{S}$ & Other \\
\hline 20GL & 0.19 & 1.33 & 0.46 & 0.21 & 0.31 & 0.25 & 0.016 & 0.006 & $\mathrm{Al}=0.03$ \\
\hline Grade 2 & 0.61 & 0.76 & 0.27 & 0.29 & 0.12 & 0.27 & 0.012 & 0.011 & $\mathrm{~V}=0.07$ \\
\hline
\end{tabular}

\section{Method of Analysis}

Preparation of the surface. The X-ray measurement site of each sample surface was subjected to grinding followed by polishing and electrolytic etching to remove work hardening which may be present on the component surface as a result of both the manufacturing and operational processes and cutting out test samples from the components.

The samples were manually grinded and polished with a portable polishing machine Accupoll by starting with P 400 lower grade grit sandpaper and ending with $\mathrm{P} 2500$ higher grit sandpaper. The surface received its final polish by means of a piece of velvet with abrasive suspension Masterprep ( 0.05 microns) applied onto it. The polishing process took $2-3 \mathrm{~min}$ and resulted in the polished surface having a mirror bright finish. To remove the work-hardened layer, electrolytic etching using a $4 \% \mathrm{HNO}_{3}$ solution in ethanol to a total depth of $200 \mu \mathrm{m}$ was carried out by use of an electrolytic etcher Polimat 2. Each sample was prepared for the study in the middle of its surface (Fig. 1).

Mechanical loading. The tensile stress was created by placing the samples under load by the three-point bending method in a special loading device (Fig. 2).

Stress was created by applying a load to the middle of the sample by driving a screw. Surface stress measurements were made at a point opposite to the point of load application located on the surface of the deformed sample. The value of stress created was set by turning the loading screw a set number of times. Preliminary calculations showed that a significant surface elastic tensile stress which would not

Fig. 1 The appearance of a sample to measure surface stresses

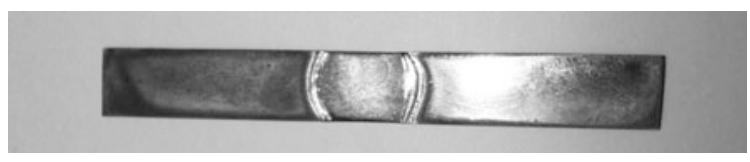

Fig. 2 Loading the sample with the loading device by the three point bending method (the screw is turned to 0.25 turn); 1 surface stress measuring point; 2 loading screw

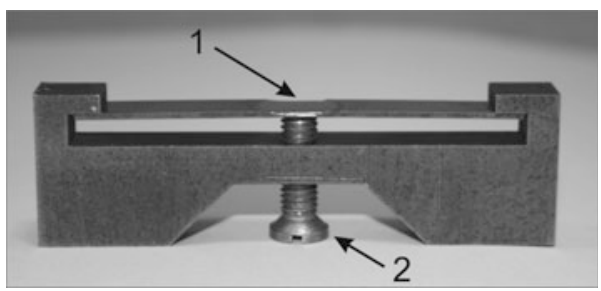


exceed the yield strength of material could be created by taking $0.5-1$ full turns on the screw. This is the way each sample was tested under the same loading to determine surface stresses.

Stress Measurements. Stress measurements were performed by means of a mock-up of the portable X-ray diffractometer originally designed and a serial stationary X-ray diffractometer Rigaku SmartLab. When preparing a sample for measurements it was put under pressure by taking turns on the loading device screw, so that the sample experienced stress in its central part. The screw was turned $0.5,0.75$, and 1.0 full turns.

The designed portable X-ray diffractometer included the following main units: a position-sensitive detector; two X-ray tubes combined with collimation devices; a goniometer; a special tripod for mounting the goniometer and its location relative to a measured component; laser tuning and alignment devices; a power supply unit and electronics interfaced with a personal computer. The design of the tripod and goniometer allows the Bragg plane where X-ray tubes and detector located to be tilted forward and backward at $30^{\circ}$ in the frontal direction (Fig. 3).

The measurements were performed using the method of slope. Diffraction peaks were recorded using $\mathrm{CrK} \alpha$ radiation for multiple locations of the X-ray tube (angle values $=0^{\circ}, 10^{\circ}, 20^{\circ}, 30^{\circ}$ ) from diffraction plane 211 . Then the locations of the "centers of gravity" of the diffraction peaks were determined after cutting out the background by means of special software "StressControl" and auxiliary applications.

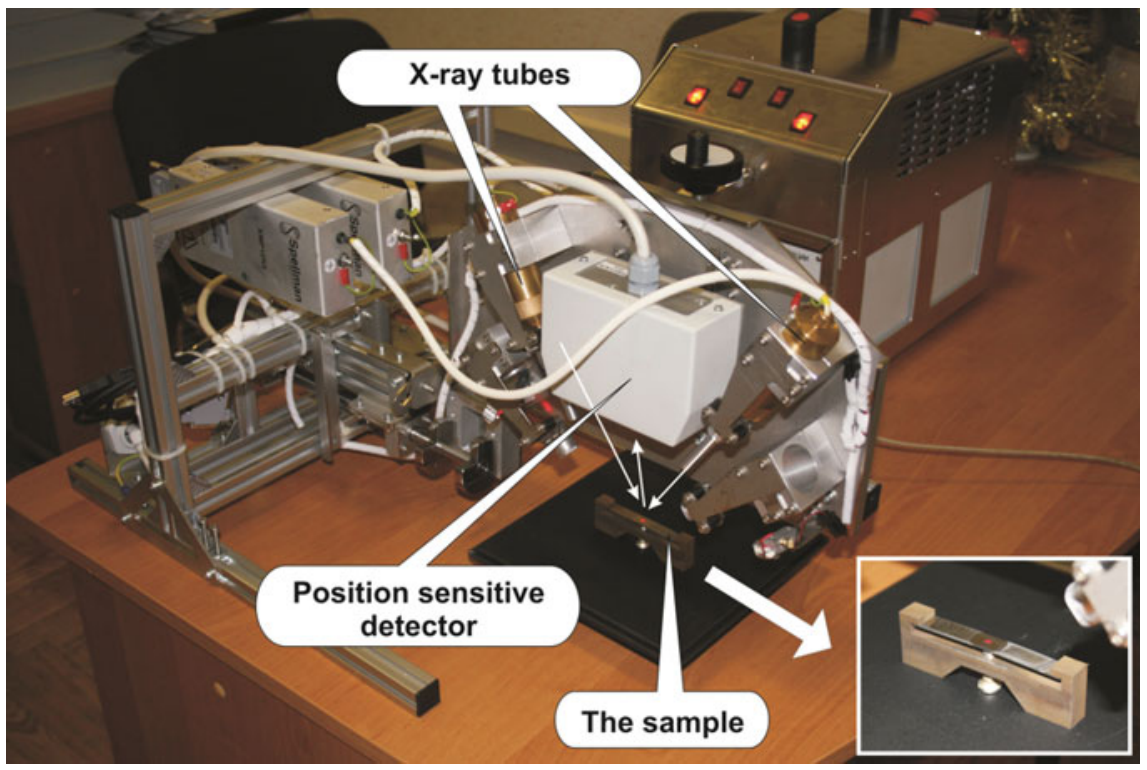

Fig. 3 The sample placed under portable X-ray diffractometer 
A linear relationship between relative deformation $\varepsilon$ and angle shift of diffraction peak allowed using generalized Hook's Law, to determine surface stress $\sigma$ in the direction normal to the tilting axis of a Bragg plane on the specimen surface through a tangent of the slope of the straight line $\varepsilon=k \times \sin ^{2} \psi+b$, where $\sigma=k \times E /(1+\mu)$, where $E, \mu-\mathrm{X}$-ray elastic constants (elasticity modulus, Poisson ratio), $\mathrm{b}$ - unspecified coefficient which determines straight line position at $\psi=0^{\circ}$.

To verify the test results, additional measurements were made on the same samples held under the same loading conditions using the multipurpose X-ray diffractometer Rigaku SmartLab (Fig. 4) and with application of $\mathrm{CuK} \alpha$ radiation and a graphite monochromator. Measurements of stress were conducted by the " $\sin ^{2} \psi$ " method in the "pseudo" slope of the sample, i.e., by the method of rotations. A diffraction plane was used (310) to analyze macro-stresses. Diffraction peaks were registered by use of a parallel X-ray beam to reduce the effects of tilt defocus. The sample was tilted (turned) by $\psi=0^{\circ} ; 30^{\circ} ; 45^{\circ}$ and $60^{\circ}$.

After this, analogous to measurements by portable X-ray device, data were processed with software the stress magnitude was calculated by

- determining the position of the centers of gravity of the diffraction peaks ( $2 \theta$ value) after the background has been cut out, where $\theta$-diffraction angle;

- calculating the relative deformation of the sample $\varepsilon$ caused by loading applied by formula:

$$
\varepsilon=\operatorname{ctg} \theta_{0}\left(\theta_{0}-\theta_{\psi}\right)
$$

Fig. 4 The sample placed in the loading device shown in the chamber of the X-ray diffractometer Rigaku SmartLab with designated angles

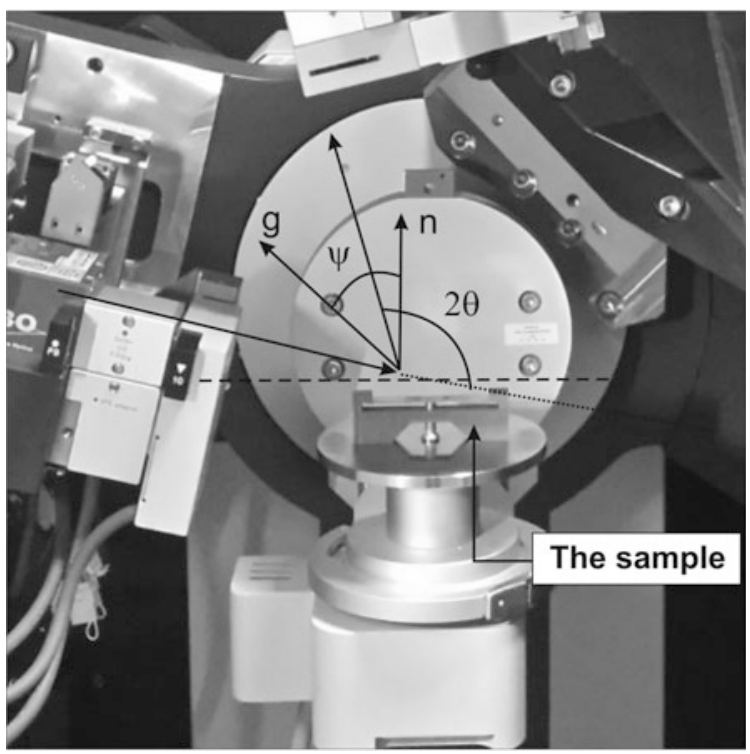


where $\theta_{0}$ is the initial angle of diffraction. This corresponds to a specimen in unloaded condition; $\theta_{\psi}$ is the offset angle of diffraction (formed by deformation under slope of a Bragg plane to the angle);

- using the $\ll \sin ^{2} \psi \gg$ method to build a graphical dependence between the relative deformation $\varepsilon$ of the crystal lattice and $\sin ^{2} \psi$ in the direct form $\varepsilon=k \sin ^{2} \psi+b$ by the method of least squares. The magnitude of the residual stress in the direction on the specimen surface coinciding with the Bragg tilt plane (normal to tilting axis of a Bragg plane) was determined on the basis of the linear relationship built. The magnitude of the stresses is proportional to the tangent of the slope of the linear relationship established (2):

$$
\sigma=k \frac{E}{1+\mu},
$$

where $E$ and $\mu$ are Young's modulus and Poisson's ratio for this material correspondingly;

$\sigma$ is the stress in a given direction.

Relative error of stress value under all measurements was determined taking into account a scatter of diffraction peak locations for different $\psi$ angles.

\section{Analysis Results}

The results of the stress measurements are shown in Table 2, and Fig. 5 illustrates the dependence between the surface stresses measured and the magnitude of deformation.

Table 2 and Fig. 5 make is evident that the surface tensile stresses measured on all the samples by use of both diffractometers increase linearly with further increase

Table 2 Tensile stress measurements results obtained on the steel samples

\begin{tabular}{l|l|l|l|l}
\hline Steel & $\begin{array}{l}\text { Heat } \\
\text { treatment }\end{array}$ & $\begin{array}{l}\text { Number of } \\
\text { screw } \\
\text { turns, } \mathrm{n}\end{array}$ & $\begin{array}{l}\text { Stress obtained by the } \\
\text { stationary } \\
\text { diffractometer, MPa }\end{array}$ & $\begin{array}{l}\text { Stress obtained by the } \\
\text { portable } \\
\text { diffractometer, MPa }\end{array}$ \\
\hline \multirow{2}{*}{\begin{tabular}{l} 
Grade \\
\cline { 3 - 5 }
\end{tabular}} & Annealing & 0.00 & - & 0 \\
\cline { 3 - 5 } & Normalization & 0.00 & +37 & 0 \\
\cline { 3 - 5 } & 0.50 & +147 & +240 \\
\cline { 3 - 5 } & 0.75 & +213 & +280 \\
\cline { 3 - 5 } & 1.00 & +279 & +330 \\
\hline \multirow{2}{*}{$20 \mathrm{GL}$} & Annealing & 0.00 & - & 0 \\
\cline { 3 - 5 } & Normalization & 0.00 & +40 & +20 \\
\cline { 3 - 5 } & & 0.50 & +181 & +220 \\
\cline { 3 - 5 } & & 0.75 & +254 & +280 \\
\hline
\end{tabular}



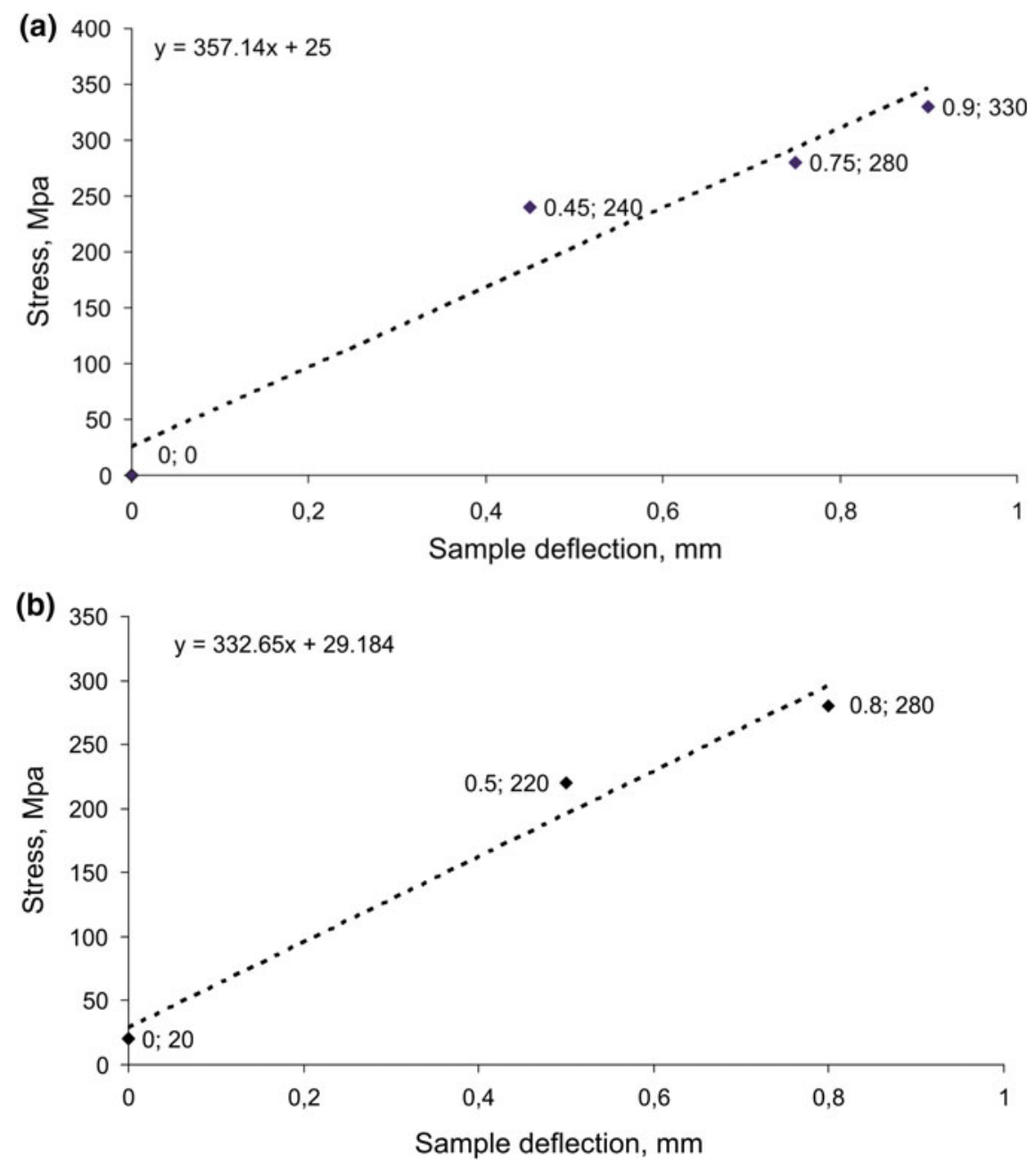

Fig. 5 Relation between stresses and deflection determined on the samples in the three point binding: a grade 2 steel sample, GOST 10791, after normalization; b the 20GL steel sample after normalization

of each sample deflection. For the annealed samples, as expected, the value of residual stresses is equal to zero (under zero deflection).

Table 2 shows good coincidence of the results obtained by the portable and stationary diffractometers, in particular when the screw is turned to 1 turn (maximum tensile stress).

When the screw is less 1 turn out (0.5), which results in lower tensile stress, there is a greater discrepancy in the results which can be explained by errors in the calculation of diffraction peaks with a slight (weak) shift of the diffraction peak relative to its position in the unstrained condition. 


\section{Conclusions}

1. By displaying zero values stress measurements performed on all the annealed samples proved the correctness of the angular setting of the portable X-ray diffractometer and pointed out the possibility of using such samples to conduct a preliminary check on the angular setting and efficiency of the portable X-ray diffractometer.

2. Tensile stress measurements performed by means of the portable and stationary $\mathrm{X}$-ray diffractometers showed a linear increase in tensile stress with increasing degree of deformation by bending in all the samples.

3. The comparison of the surface stress measurements performed on the steel samples by use of the portable X-ray diffractometer with the measurement results obtained by the stationary X-ray diffractometer and calculations made showed a good concurrence in the stress values to within an accuracy of $10 \%$ (adjusted for calculation and measurement errors).

Acknowledgements Researches are carried out with the financial support of the state represented by the Ministry of Education and Science of the Russian Federation. Agreement no. 14.578.21.0020 06.June 2014. Unique Project Identifier: RFMEFI57814X0020.

\section{References}

1. Anisimov, V.A., Katorgin, B.I., Kutsenko, A.N., others.: Acoustical Tensometry. In: Non-Destructive Control. Directory. Under the general editorship of Kluev V.V., 8 vols. V. 4, 736 p, book 1, Mashinostroenie, Moscow (2006)

2. Kluev, V.V.: Magnetic Control Methods. In: Non-Destructive Control. Directory in 8 volumes under the editorship of Kluev V.V., corresponding member of the Russian Academy of Sciences, vol. 6, 848 p, Book 1/ Kluev V.V. Muzhitsky V.F., Gorkunov E.S., others, Mashinostroenie, Moscow (2006)

3. Pankovsky, Y.P.: Hardware realization of certain magnetic non-destructive control methods. World Meas. (5), 9-12 (2005)

4. Prilutsky, M.A.: Methods of Assessment of Welded Metal Structure Strain-Stress State. News of High Schools, Mashinostroenie. (2008), N. 4, pp. 45-50

5. Kraus, I., Ganev, N.: X-ray analysis of the inhomogeneous stress state. In: Snyder, R., Fiala, J., Bunge, H.-J. (eds.) Defect and Microstructure Analysis by Diffraction, pp. 367-401. Oxford University Press (1999)

6. Noyan, I.C., Cohen, J.B.: Residual Stress Measurements by Diffraction and Interpretation. Springer, NY (1987)

7. Vasiliev, D.M.: Diffraction Methods for Structure Analysis, 502 p. The Saint-Petersburg State Technical University, Saint-Petersburg (1998)

8. Sosnin, F.R.: Radiation control. In: Non-Destructive Control. Directory in 8 volumes under the editorship of Kluev V.V., corresponding member of the Russian Academy of Sciences, vol. 1, 560 pp. Book 2. Mashinostroenie, Moscow (2003) 
9. Enisherlova, K.L., Lutzau, A.V., Temper, E.M., Gorjachev, V.G., Tkacheva, T.M.: Combined investigation of silicon-on-insulator structures. In: SILICON 2010, 12 Scientific and Business Conference Roznov pod Radhostem, Czech Republic, 2-5 Nov 2010, pp. 315-331

10. Luttsau, A.V., Krymko, M.M., Enisherlova, K.L., Temper, E.M., Razgulyaev, I.I.: Analysis of heterostructures by the one-crystal x-ray diffraction method. In: Electronics Engineering Materials, pp. 72-78. (2012)

Open Access This chapter is licensed under the terms of the Creative Commons Attribution 4.0 International License (http://creativecommons.org/licenses/by/4.0/), which permits use, sharing, adaptation, distribution and reproduction in any medium or format, as long as you give appropriate credit to the original author(s) and the source, provide a link to the Creative Commons license and indicate if changes were made.

The images or other third party material in this chapter are included in the chapter's Creative Commons license, unless indicated otherwise in a credit line to the material. If material is not included in the chapter's Creative Commons license and your intended use is not permitted by statutory regulation or exceeds the permitted use, you will need to obtain permission directly from the copyright holder.

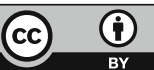

